\title{
Differences and Relationships Between the Physical Properties and the Microscopic Structure of Human Femoral, Tibial and Fibular Cortical Bone'
}

\author{
F. GAYNOR EVANS AND SEONG BANG \\ The University of Michigan, Ann Arbor, Michigan
}

\begin{abstract}
Coefficients of correlation between certain physical properties and the histological components of the break area were calculated on an IBM 7090 computer for 56 femoral, 79 tibial and 37 fibular specimens of embalmed cortical bone of standardized size and shape. Strong positive correlations (0.01-0.02 significance level) were found between tensile strength and the percentage of interstitial lamellae in the break area; between hardness and the number of osteons $/ \mathrm{mm}^{2}$; and between hardness and the percentage of osteons in the break area. Equally high negative correlations were found between tensile strength and percentage of osteons in the break area; between shearing strength and average area/osteon remnant; between elastic modulus and percentage of spaces in the break area; and an even higher correlation ( 0.001$)$ between hardness and percentage of spaces in the break area. Negative correlations (at slightly more than 0.05 significance level) were found between shearing strength and modulus and average area/osteon. Osteons tend to reduce the tensile strength and elastic modulus of bone while interstitial lamellae tend to increase them. The probable reason is the relatively greater amount of cement lines, which are sites of weakness where failure can occur, in Haversian bone as compared with lamellar bone. The predominant orientation of collagen fibers and the amount and distribution of calcium may also be involved. These factors are now being investigated.
\end{abstract}

The present paper is a supplement to our previous one ('66) on the relations between statistically significant differences in the physical properties and microscopic structure of adult human femoral and fibular cortical bone. The physical properties investigated (ultimate tensile strength, single shearing strength, tensile strain, tangent modulus of elasticity, hardness, density, and the ratio of single shearing strength to ultimate tensile strength) and their relation to osteons, remnants or fragments of osteons, interstitial lamellae, and spaces are the same as in our previous investigation.

Our studies relate more physical properties of bone to its microscopic structure than do the investigations of Maj and Toajari ('37), Olivo, Maj and Toajari ('37), Olivo ('37), Maj ('38), Toajari ('38, '39), Evans ('57, '58), Currey ('59, '62, '64), Dempster and Coleman ('61), and Heřt et al. ('65). The majority of these investigations were on the relation of tensile strength and/or modulus of elasticity of bone to the osteons or collagen fiber distribution although Currey ('64) discussed the possible relation of bone strength to the apatite crystals while Herrt et al. ('65) investigated the relation of compressive strength, impact bending strength and microhardness to primary and Haversian bone. Nonhuman bone was usually used in these studies but none of them related statistically significant differences in the physical properties of the bone to its microscopic structure.

\section{MATERIALS AND METHODS}

The physical properties investigated in the present study were determined for 405 femoral, 193 tibial and 37 fibular specimens of cortical bone which were machined to a standardized size and shape from the proximal, the middle and the distal thirds of the shaft of the respective bones. The specimens were obtained from

\footnotetext{
1 This research was supported (in part) by Research grant AM-03865-07 from the National Institutes of Health, U.S. Public Health Service.
} 
the embalmed bodies of 11 white males, one Negro male and four white females ranging from 33 to 98 years of age. None of the individuals had died from primary bone diseases (table 1) and all the bones appeared to be normal. The older individuals, especially the women, very probably had senile osteoporosis although this was not confirmed by x-ray examination. Embalmed material was used because the only unembalmed femoral material was from above-knee amputations in which only the distal third of the femur was present. Wet specimens were used for all determinations of physical properties except density.

The methods for determining the physical properties of the specimens were the same as those employed by Evans and Lebow ('51, '52). Some comments on the determination of hardness and density may be helpful because the hardness of bone has not been investigated much in the past and the method of determining density was especially developed by Evans, Coolbaugh and Lebow ('51) for their studies on bone.

The hardness of the specimens was determined with a Rockwell superficial hardness tester (see Cowdrey and Adams, '44, for details) which measures the resistance of a material to penetration by a hardened steel ball or by a diamond cone. Two scales of values, $\mathrm{B}$ for ball and $\mathrm{C}$ for cone, are available for use. The $B$ scale was used in the present studies in which a steel ball, one-eighth inch in diameter, was loaded with $45 \mathrm{~kg}$ for ten seconds. The value for hardness was obtained from the average of four tests, two on each side of the specimen. With the Rockwell method any penetration less than a certain depth gave a negative (-) value for the hardness of the material being tested. This explains the presence of negative hardness values for some of the specimens.

The density determinations were made on air dried specimens to prevent moisture from being entrapped within the spaces of the specimens. Corrections were not made for air in the spaces because they would not cause any significant differences in the results. Strontium 90 was used in the density determinations, the density of the specimen being based upon the percentage of transmission of beta rays through the specimen in a given amount of time (see Evans, Coolbaugh and Lebow, loc. cit., for details).

Transverse sections, taken as near the fracture site as possible, of randomly selected specimens were analyzed with respect to the percentage of spaces, osteons, remnants or fragments of osteons and interstitial lamellae in the sections. Photographs of the sections were taken under ordinary light with a Zeiss photomicroscope and prints, enlarged to a standardized size, were made on photographic paper of a constant known weight. The enlarged prints were then analyzed with respect to the above mentioned histological elements by the photomicrographweight method used by Evans ('58) and Evans and Bang ('66).

TABLE 1

\begin{tabular}{rrlll}
\hline $\begin{array}{c}\text { Cadaver } \\
\text { no. }\end{array}$ & Age & Sex & Race & \multicolumn{1}{c}{ Cause of death } \\
\hline 1342 & 33 & Female & White & Severe uterine hemorrhage \\
657 & 64 & Male & White & Myocardial infarct \\
987 & 70 & Male & White & Pulmonary tuberculosis \\
1112 & 63 & Male & White & Pneumonia \\
1081 & 65 & Male & White & Cerebral hemorrhage \\
804 & 58 & Male & White & Infectious hepatitis \\
1070 & 47 & Male & White & Pul. Tb. \\
1087 & 78 & Male & White & Coronary occlusion \\
213 & 81 & Male & White & Arteriosclerotic heart disease \\
1434 & 69 & Female & White & Cerebral vascular hemorrhage \\
1121 & 36 & Male & White & Pul. Tb. \\
1143 & 47 & Male & White & Bronchiogenic carcinoma \\
1240 & 66 & Male & White & Myocardial infarct \\
1128 & 72 & Male & Negro & Pul. Tb. \\
1742 & 90 & Female & White & Arteriosclerotic heart disease \\
1552 & 98 & Female & White & Acute myocardial infarct \\
\hline
\end{tabular}


The physical property and histological data were subjected to an analysis of variance on an IBM 7090 computer in The University of Michigan Computing Center to determine if the differences between the means for the various physical properties and histological elements were statistically significant. Coefficients of correlation between the physical properties and histological elements were also computed. Since $5 \%$ variation is generally assumed to be normal in biological material, only differences with a significance level greater than 0.05 were considered.

\section{RESULTS}

Average values for the various physical properties of the femoral, the tibial and the fibular specimens (figs. 1,2) showed that the tibial specimens had the greatest ultimate tensile and single shearing strength and were the densest. The fibular specimens were the stiffest (highest modulus of elasticity) and had the greatest tensile strain ( $1 \%$ elongation). The femoral specimens were the hardest, the weakest (tensile and shearing strength), the least stiff and had the least tensile strain. The fibular specimens were the softest and the least dense.

An analysis of variance of these data revealed differences, at the $1 \%$ or better significance level, between the physical properties of the different specimens. Comparison of the femoral and the tibial specimens showed that the latter were significantly stronger (ultimate tensile and shearing strength), stiffer (modulus of elasticity), denser and exhibited greater tensile strain than did the femoral specimens. The fibular specimens also had a significantly greater ultimate tensile strength and a higher modulus of elasticity than the femoral specimens. The tibial specimens were significantly denser than the fibular ones.

The single shearing strength of the fibular specimens was greater than that of the femoral ones but the latter were denser than the former at the $5 \%$ significance level. There were no significant differ-

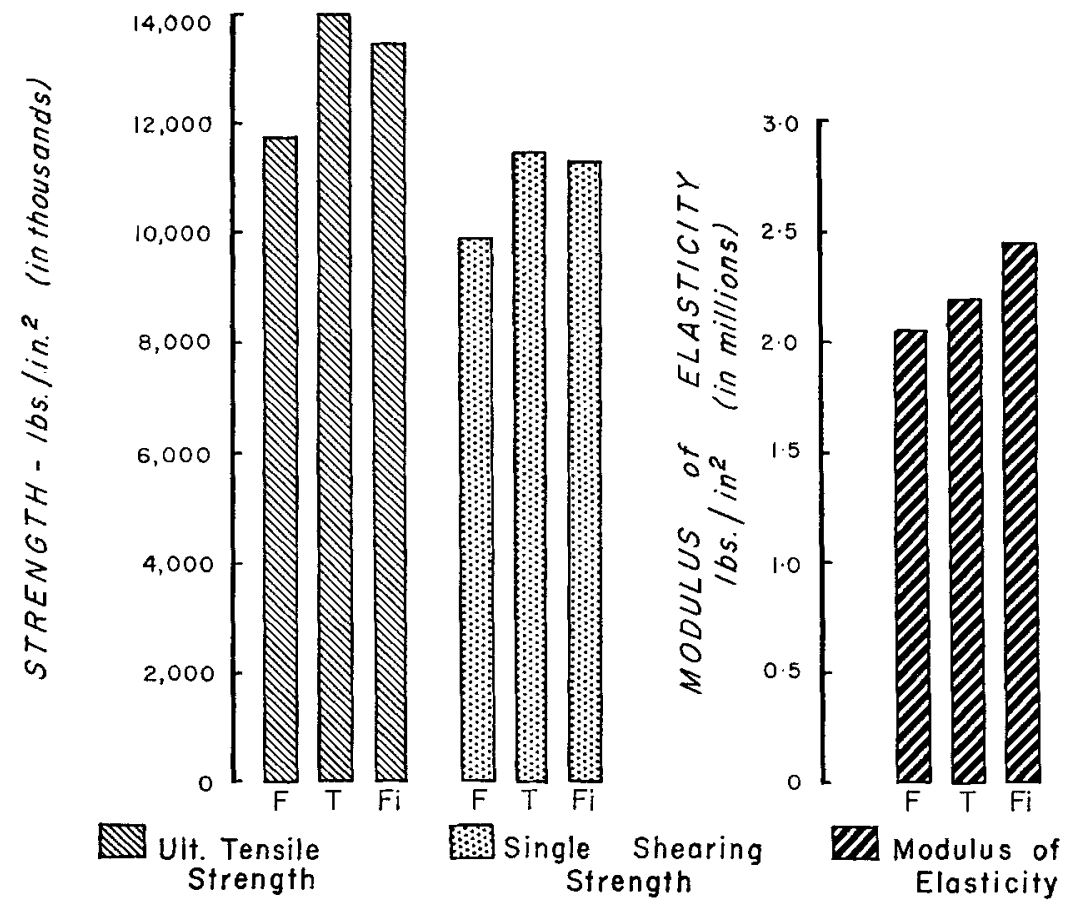

Fig. 1 Average values for tensile and shearing strength and modulus of elasticity of human bone. The number of specimens is indicated above the bars. 
ences in the hardness of the various specimens.

The results of the histological analysis of the corrected break area of the specimens, in terms of the percentage of the area formed by the various histological components of the sections, are presented diagrammatically in figure 3 . The corrected break area is obtained by substracting the area of spaces (Haversian canals, resorp-

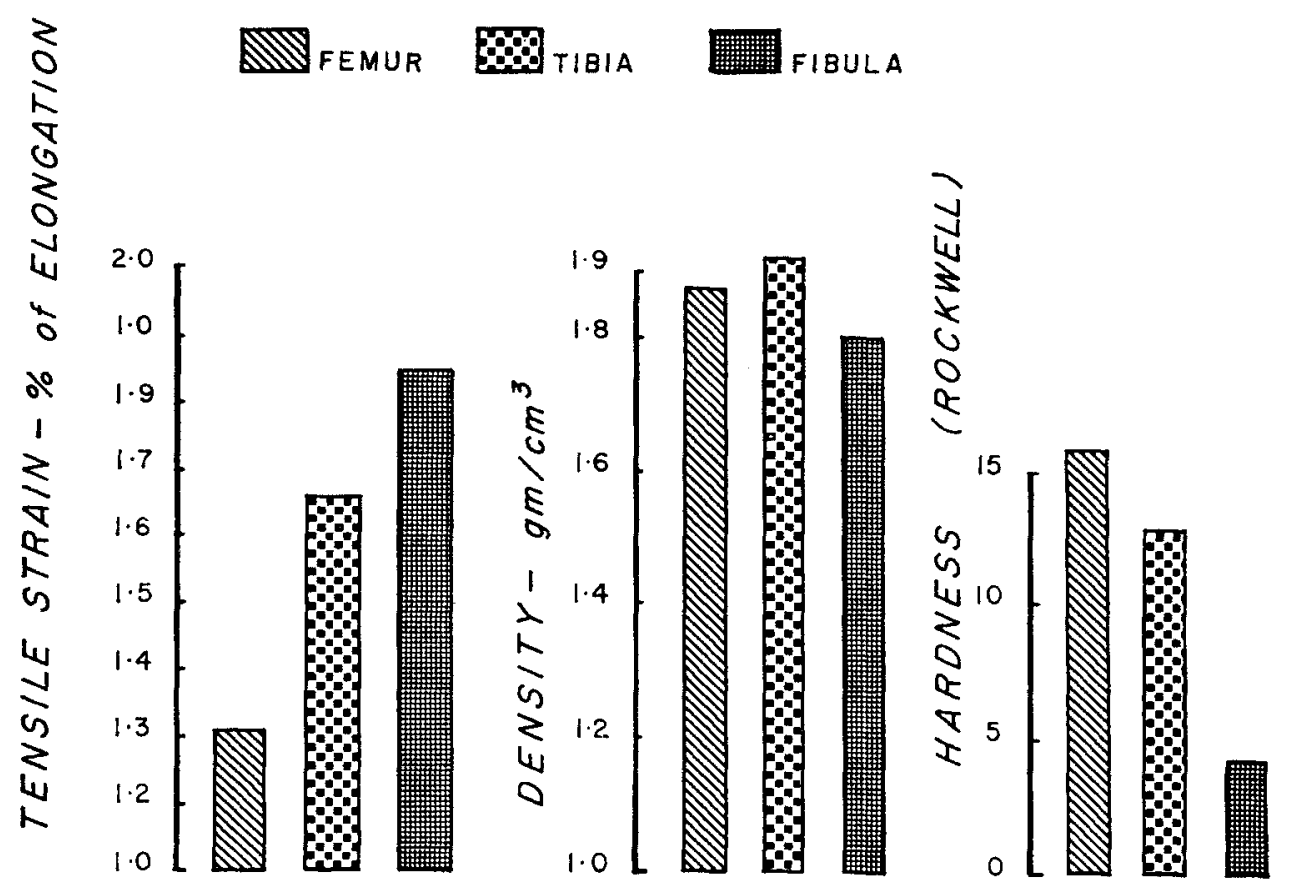

Fig. 2 Average values for tensile strain ( $\%$ elongation), density and hardness of human bone.
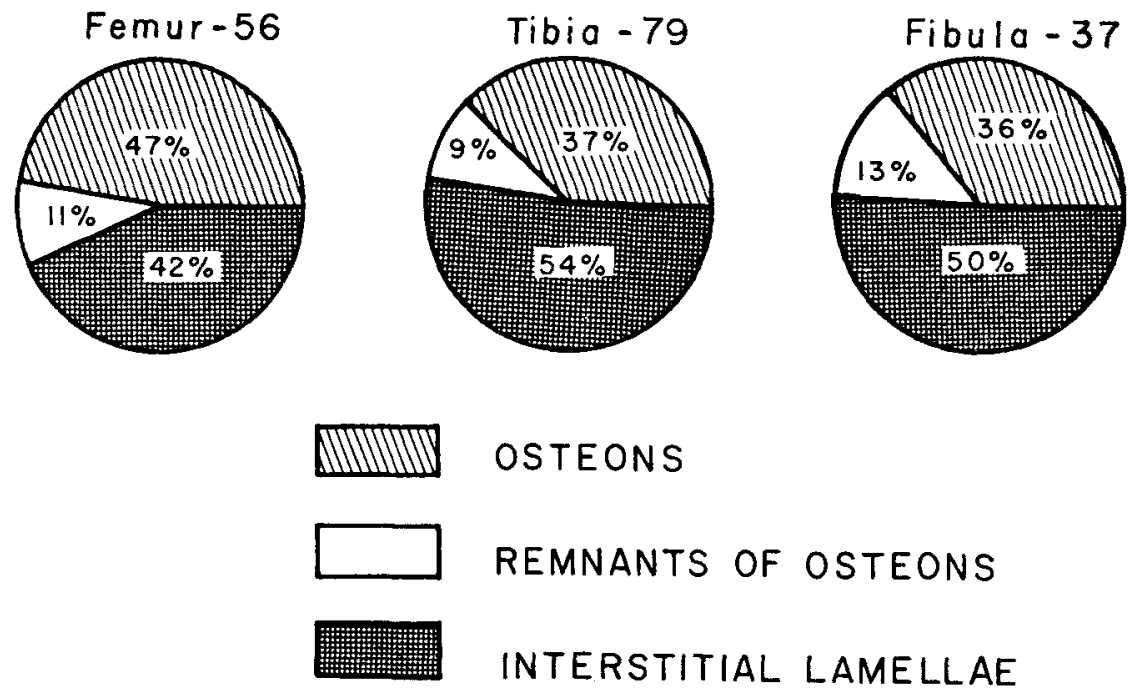

OSTEONS

REMNANTS OF OSTEONS

INTERSTITIAL LAMELLAE

Fig. 3 Percentage of corrected break area formed by various histological components of bone. See text for definition of corrected break area. 
tion spaces, etc.) from the original break area of the specimen as measured with calipers at the time of the test. The corrected break area was always smaller than the original break area because the caliper measurements of the break area did not allow for irregularities in the margins of the section nor for spaces within the section.

Comparison of the histological components of the corrected break area of the femoral, the tibial and the fibular specimens showed that the percentage of the area formed by osteons was the greatest in the femoral sections and the least in the fibular ones. The fibular sections had the highest percentage of the area formed by remnants of the osteons; the tibial sections the lowest percentage. The proportion of interstitial lamellae was greatest in the tibial sections and least in the femoral ones.

The sections from the three bones also exhibited differences in the average number of osteons and osteon remnants per square millimeter (fig. 4) and in the aver- age area (square micra) per osteon and per osteon remnant (fig. 5). The femoral sections had the laregst number of osteons / $\mathrm{mm}^{2}$ while the fibular sections had the fewest. The largest number of osteon fragments $/ \mathrm{mm}^{2}$ was found in the tibial sections and the lowest in the femoral sections. The fibular sections had the largest osteons and osteon fragments; the tibial sections the smallest ones.

An analysis of variance between the histological components of the femoral and tibial sections revealed the following differences at the $1 \%$ or better significance level. The femoral sections had larger osteons and remnants of osteons (area in square micra) than did the tibial sections and they formed a larger percentage of the corrected break area. The percentage of the original break area formed by spaces and of the corrected break area formed by interstitial lamellae was significantly greater in the tibial sections than in the femoral ones.

Similar comparison of the femoral and fibular sections showed that the femoral
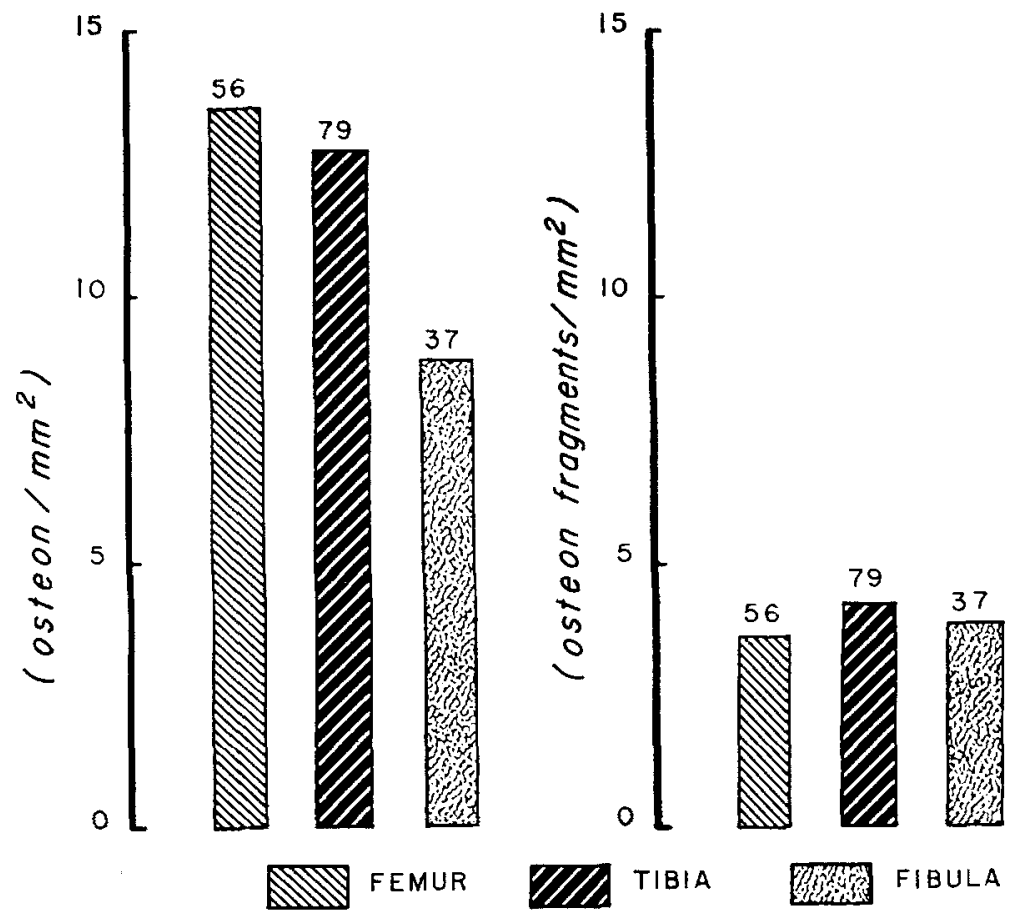

Fig. 4 Average number of osteons and their fragments per $\mathbf{m m}^{2}$ of human bone. 

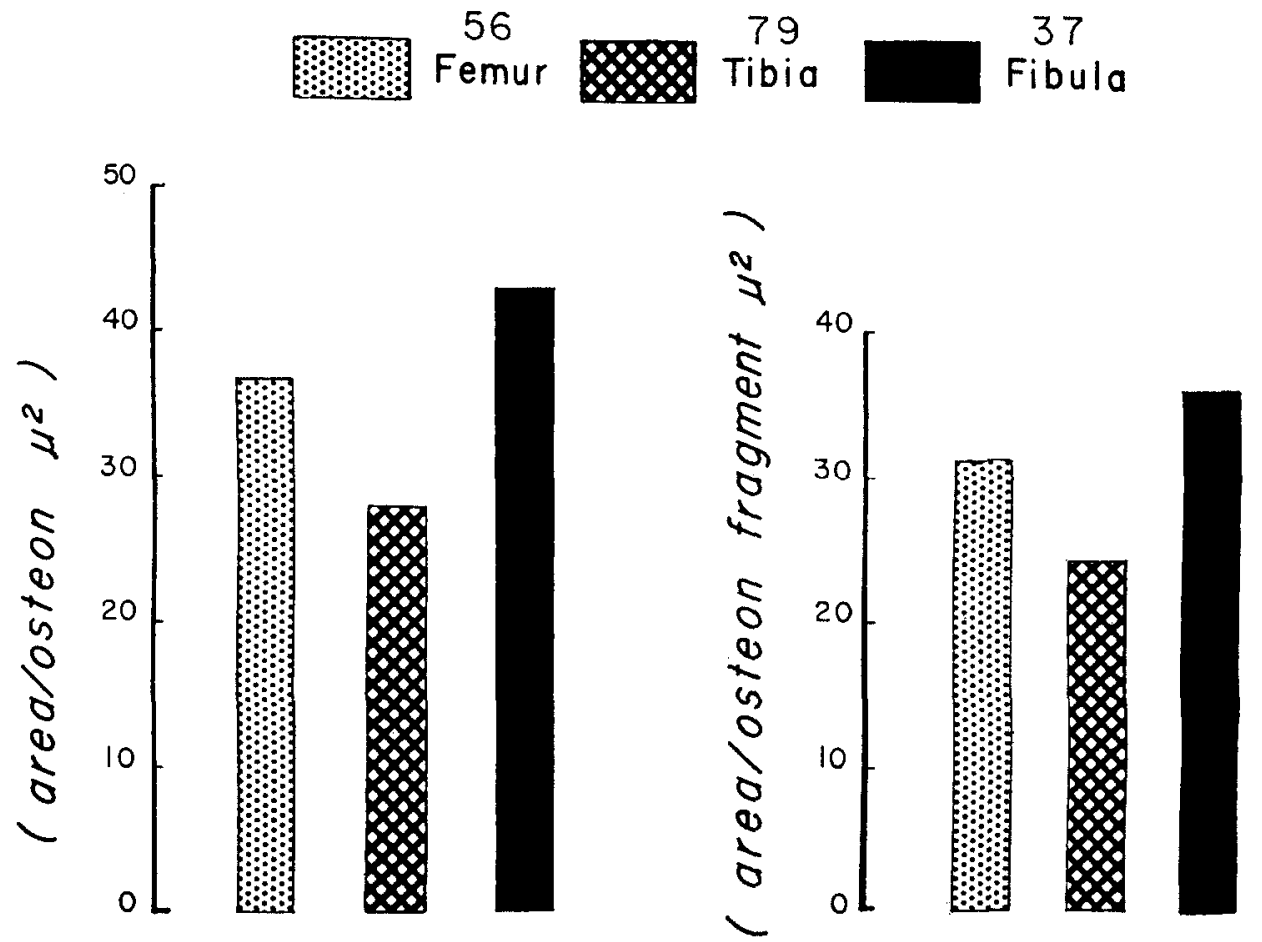

Fig. 5 Average area $\left(\mu^{2}\right)$ per osteon and per osteon fragment in human bone.

sections had significantly more osteons/ $\mathrm{mm}^{2}$ and a significantly greater percentage of the corrected break area formed by osteons than did the fibular sections. The latter had a significantly greater percentage of the corrected break area formed by interstitial lamellae.

An analysis of the tibial and the fibular sections revealed that the tibial sections had significantly more osteons $/ \mathrm{mm}^{2}$ and a greater percentage of the corrected break area formed by interstitial lamellae than did the fibular sections. However, the fibular sections had significantly larger osteons and osteon remnants (area in square micra) than did the tibial sections.

\section{DISCUSSION}

The finding of some highly significant differences between certain physical properties and histological components of human cortical bone raises the question as to whether or not differences in the physical properties of bone show a significant correlation with its histological components. In order to answer this question coefficients of correlation between the physical properties and histological components of more than 100 transverse sections of standardized specimens of human femoral, tibial and fibular bone were calculated on an IBM 7090 computer in The University of Michigan Computing Center.

The results of this analysis (table 2) reveal a high positive correlation between ultimate tensile strength (UTS) and the percentage of the corrected break area (CBA - see text for definition) formed by interstitial lamellae; between hardness and the number of osteons $/ \mathrm{mm}^{2}$; and between hardness and the percentage of the corrected break area formed by osteons.

High negative correlations are found between ultimate tensile strength and the percentage of the corrected break area formed by osteons; between the modulus of elasticity (E) and the average area/ osteon; between the modulus of elasticity and the percentage of the original break area (OBA - see text for definition) formed by spaces; between single shearing (punching) strength (SSS) and the average area/ 
TABLE 2

Correlation between physical properties and histological elements of embalmed human cortical bone (femur, tibia and fibula)

\begin{tabular}{|c|c|c|c|c|}
\hline Variables & $\begin{array}{l}\text { Adjusted } \\
\text { number }\end{array}$ & $\begin{array}{l}\text { Correlation } \\
\text { coefficient } \\
(\mathbf{R})\end{array}$ & $\begin{array}{c}\text { T-test } \\
(\mathbf{T})\end{array}$ & $\begin{array}{c}\text { Significance } \\
\text { level }\end{array}$ \\
\hline E vs avg area/osteon & 115 & -0.195 & -2.109 & $>0.05$ \\
\hline E vs \% OBA-spaces & 115 & -0.242 & -2.648 & $>0.01$ \\
\hline UTS vs $\%$ CBA-osteons & 119 & -0.236 & -2.628 & $>0.01$ \\
\hline UTS vs \% CBA-interst. lamellae & 119 & 0.233 & 2.592 & $>0.02$ \\
\hline SSS vs avg area/osteon & 118 & -0.188 & -2.060 & $>0.05$ \\
\hline SSS vs avg area/osteon remnant & 118 & -0.230 & -2.541 & $>0.02$ \\
\hline Hardness vs no. osteon $/ \mathrm{mm}^{2}$ & 113 & 0.259 & 2.827 & 0.01 \\
\hline Hardness vs $\%$ CBA-osteons & 113 & 0.246 & 2.675 & $>0.01$ \\
\hline Hardness vs \% OBA-spaces & 113 & -0.367 & -4.158 & $>0.001$ \\
\hline
\end{tabular}

E, Tangent modulus of elasticity.

OBA, Original break area.

UTS, Ultimate tensile strength (stress).

CBA, Corrected break area.

SSS, Single shearing strength (stress).

No. Number of specimens.

osteon; between single shearing strength and the average area/osteon fragment; and between hardness and the percentage of the original break area formed by spaces.

The high positive correlation between ultimate tensile strength and the percentage of the corrected break area formed by interstitial lamellae and the slightly higher negative correlation between the same physical property and the percentage of the corrected break area formed by osteons suggest that interstitial lamellae tend to increase the tensile strength of cortical bone while osteons tend to reduce it. These correlations explain, in part, the significantly greater ultimate tensile strength of the tibial and the fibular specimens in comparison with that of the femoral ones because the two former kinds of specimens had a significantly greater proportion of their corrected break area formed by interstitial lamellae while the femoral specimens had a significantly greater proportion of osteons (fig. 3 ).

The probable reason, as we pointed out previously (Evans and Bang, '66), that an abundance of osteons and their remnants (fragments) tends to reduce the tensile strength of cortical bone is that Haversian bone, i.e., bone consisting mainly of Haversian systems (osteons) and their remnants, has a proportionately greater amount of cementing substance than does lamellar bone. Each osteon and osteon remnant is surrounded by a well defined cement line; therefore, the more osteons and their remnants in a given area of bone the more cement lines or cementing substance. The cement lines are not crossed by collagen fibers and represent the weakest material in bone as evidenced by the fact that fractures tend to follow the cement lines rather than to cross osteons or interstitial lamellae (Maj and Toajari, '37; Dempster and Coleman, '61; Evans and Bang, '66). Consequently, femoral bone, since it has proportionately more osteons (fig. 3) in the corrected break area as well as more osteons $/ \mathrm{mm}^{2}$ (fig. 4) than does tibial or fibular bone, has proportionately more cement lines at which failure can occur.

The greater number of osteons $/ \mathrm{mm}^{2}$ in femoral bone as compared with tibial and fibular bone (fig. 4) tend to reduce its strength for another reason. Any holes in a material tend to weaken it because each hole acts as a stress raiser, i.e., an area of higher stress concentration, where failure of the material is apt to be initiated. The Haversian canals and lacunae, as noted by Currey ('62), act as stress raisers in bone; therefore, the more osteons in a given area of bone, the more stress raisers or areas of higher stress concentration where failure can start. However, as also pointed out by Currey, the Haversian canals and the lacunae tend to limit the propagation of a microfracture because the fracture is stopped whenever it comes to a hole in the bone. 
The significantly greater single shearing strength of the tibial and the fibular specimens in comparison with the femoral ones is probably related to the fact that they have fewer osteons $/ \mathrm{mm}^{2}$ than the femoral specimens (fig. 4). Consequently, the tibial and fibular specimens have fewer cement lines where shearing can occur. The negative correlation (table 2 ) between single shearing strength and the average area per osteon and per osteon remnant may also be a contributing factor although the correlation between shearing strength and average area/osteon was only a little better than the 0.05 significance level.

The greater size (area) of the fibular osteons in comparison with the femoral ones (fig. 5) may be a contributing factor to the significantly greater modulus of elasticity of the fibular specimens because a weak negative correlation (table 2) was found between modulus and average area/ osteon. A more important factor, as previously suggested by Evans ('58) from polarized light studies, is the orientation of the collagen fibers which in the fibular specimens is predominantly parallel to the long axis of the specimen while in the femoral specimens the collagen fibers are more obliquely oriented. Therefore, the collagen fibers of the fibular specimens are in a better position to resist tensile forces than are those of the femoral specimens. Evans' suggestion has recently been confirmed by Ascenzi and Bonucci ('64) and by Ascenzi, Bonucci, and Checcucci ('66) who have shown that the tensile strength and modulus of elasticity are higher in osteons with collagen fibers nearly parallel to the long axis of the osteon. A more detailed investigation, by means of polarized light, of the relation between the physical properties and collagen fiber orientation of femoral, tibial and fibular cortical bone is now in progress in our laboratory.

The strong positive correlation between hardness and the number of osteons $/ \mathrm{mm}^{2}$ as well as the percentage of the corrected break area formed by osteons (table 2) aids in explaining the differences in the hardness of the specimens. Thus, the femoral specimens, which were the hardest (fig. 2), had the most osteons $/ \mathrm{mm}^{2}$ as well as the greatest percentage of the corrected break area formed by osteons (fig.
3) while the fibular specimens, which were the softest, had the fewest osteons $/ \mathrm{mm}^{2}$ and the lowest percentage of the corrected break area formed by osteons. However, as previously mentioned, none of the differences between the hardness of the various types of specimens was at the 0.05 or better significance level. The amount and distribution of calcium in the specimens, in addition to the relative number of older and younger osteons, are also probably related to hardness and some of the other physical properties of bone. These factors are now being investigated in our laboratory.

As would be expected, a high negative correlation was found between the amount of spaces in the original break area and the hardness and modulus of elasticity of the specimen as determined at the time of testing. However, as mentioned previously, the value for these physical properties changed somewhat when correction was made for the spaces (Haversian canals, resorption, etc.) in the original specimens.

Osteons, as we discussed in our earlier paper (Evans and Bang, '66), are not simple spool-like structures but branch or bifurcate. Consequently, the histological composition of a cross section of a specimen changes along the length of the specimen. However, the fact that the specimen failed where it did indicates that the histological composition of the specimen at the level of the fracture was weaker than in other levels of the specimen.

\section{CONCLUSIONS}

1. The ultimate tensile and single shearing strength, tensile strain, modulus of elasticity, density and hardness were determined for 405 femoral, 193 tibial and 37 fibular specimens of cortical bone of a standardized size and shape. The methods of determining the physical properties are described.

2. The specimens were obtained from embalmed bodies of 11 white males, one Negro male, and four white females ranging from 33 to 98 years of age. None of the individuals had died from primary bone disease and all the bones appeared to be normal. 
3. The histological composition of transverse sections of the specimens at the level of the fracture site was studied by the photomicrograph-weight method used in previous studies.

4. Analyses of variance were calculated on an IBM 7090 computer to determine significant differences between the physical properties and histological components of the various specimens.

5. The following differences, at the 0.01 or better significance level, were found between the physical properties of the specimens :

a. The tibial specimens had a higher tensile and shearing strength, tensile strain, modulus of elasticity and density than the femoral specimens.

b. The fibular specimens had a higher tensile and shearing strength and a higher modulus of elasticity than the femoral specimens.

c. The tibial specimens had a higher density than the fibular specimens.

6. The following differences, at the 0.01 or better significance level, were found between the histological components of 56 femoral, 79 tibial and 37 fibular transverse sections of the specimens at the level of the fracture site:

a. The femoral sections had larger osteons and remnants of osteons (square micra) and they formed a greater percentage of the break area than in the tibial sections.

b. The tibial sections had a larger percentage of the break area formed by interstitial lamellae than did the femoral sections.

c. The femoral sections had more osteons $/ \mathrm{mm}^{2}$ and a greater percentage of the break area formed by osteons than did the fibular sections.

d. The fibular sections had a larger percentage of the break area formed by interstitial lamellae than did the femoral sections.

e. The number of osteons $/ \mathrm{mm}^{2}$ and the percentage of the break area formed by osteons was greater in the tibial than in the fibular sections.

f. The fibular sections had larger osteons and remnants of osteons than the tibial sections.
7. A strong positive correlation (0.02 significance level) was found between the ultimate tensile strength of the specimens and the percentage of interstitial lamellae in the transverse sections at the level of the fracture site.

8. Hardness also showed a strong positive correlation ( 0.01 significance level) with the number of osteons $/ \mathrm{mm}^{2}$ and the percentage of osteons in the transverse sections at the level of the fracture.

9. Strong negative correlations $(0.02$ or better significance level) were found between ultimate tensile strength and the percentage of the break area formed by osteons; between single shearing strength and the average area/osteon remnant; and between hardness and the percentage of spaces in the break area.

10. Significant differences in the physical properties of femoral, tibial and fibular cortical bone are explained and discussed in terms of differences in the histological composition of the specimens at the level of the fracture site.

\section{LITERATURE CITED}

Ascenzi, A., and E. Bonucci 1964 The ultimate tensile strength of single osteons. Acta anat. (Basel), 58; 160-183.

Ascenzi, A., E. Bonucci and A. Checcucci 1966 The Tensile Properties of Single Osteons Studied Using a Microwave Extensimeter. In: Studies on the Anatomy and Function of Bone and Joints. Ed. by F. G. Evans. Springer-Verlag, Heidelberg. 121-141.

Cowdrey, I. H., and R. G. Adams 1944 Materials Testing; Theory and Practice. John Wiley and Sons, Inc., New York, 1-156.

Currey, J. D. 1959 Differences in the tensile strength of bone of different histological types. J. Anat., 93: 87-95.

1962 Stress concentrations in bone. $J$. Microscopical Sci., 103: 111-133.

1964 Mechanical aspects of the structure of bone. (Abstract presented at the Bone and Tooth Society, London, September 25, 1963 ). J. Bone Joint Surg., 46B: 356.

Dempster, W. T., and R. F. Coleman 1961 Tensile strength of bone along and across the grain. J. Appl. Physiol., 16: 355-360.

Evans, F. G. 1957 Stress and Strain in Bones. Charles C Thomas, Springfield, Ill., 1-245.

- 1958 Relations between the microscopic structure and tensile strength of human bone. Acta Anat., 35: 285-301.

Evans, F. G., and S. Bang 1966 Physical and Histological Differences between Human Fibular and Femoral Compact Bone. In: Studies on the Anatomy and Function of Bone and Joints. Ed. by F. G. Evans. Springer-Verlag, Heidelberg. 142-155. 
Evans, F. G., C. C. Coolbaugh and M. Lebow 1951 An apparatus for determining bone density by means of radioactive strontium $\left(\mathrm{Sr}^{90}\right)$. Science, 114: 182-185.

Evans, F. G., and M. Lebow 1951 Regional differences in some of the physical properties of the human femur. J. Appl. Physiol, 3: 563-572.

1952 The strength of human compact bone as revealed by engineering technics. Am. J. Surg., 83: 326-331.

Heřt, J., P. Kučera, M. Vávra and V. Voleník 1965 Comparison of the mechanical properties of both the primary and haversian bone tissue. Acta Anat., 61; 412-423.

Maj, G. 1938 Osservazioni sulle differenze topografiche della resistenza meccanica del tessuto osseo di uno stesso segmento scheletrico. Monitore Zool. Ital., 49: 139-149.
Maj, G., and E. Toajari 1937 Osservazioni sperimentali sul meccanismo di resistenza del tessuto osseo lamellare compatto alle azioni meccaniche. Chir. Organi Mov., 22: 541-557.

Olivo, O. M. 1937 Rispondenza della funzione meccanica varia degli osteoni con la loro diversa minuta architettura. Boll. Soc. Ital. Biol. Sper., 12: 400-401.

Olivo, O. M., G. Maj and E. Toajari 1937 Sul significato della minuta struttura del tessuto osseo compatto. Boll. Sci. Med. Bologna, 109: 369-394.

Toajari, E. 1938 Resistenza meccanica ed elasticità del tessuto osseo studiata in rapporto alla minuta struttura. Monitore Zool. Ital., 48: 148-154.

- 1939 Differenze nella struttura e resistenza meccanica del tessuto osseo in due razze Bos. Taurus. Arch. Sci. Biol. (Bologna), 25: 544-557. 